\title{
Hydrogenation in vitro of $\alpha$-Linolenic Acid to Stearic Acid by Mixed Cultures of Pure Strains of Rumen Bacteria
}

\author{
By PATRICK KEMP* AND DAVID J. LANDER \\ Biochemistry Department, ARC Institute of Animal Physiology, Babraham, \\ Cambridge CB2 4AT, UK
}

(Received 11 August 1983; revised 16 November 1983)

The hydrogenation of $\alpha$-linolenic acid to stearic acid which occurs with the mixed bacteria of the sheep rumen can be demonstrated in vitro by mixing exponential phase cultures of only two species of rumen bacteria and incubating for a further period with $\alpha$-linolenic acid. One bacterium must be able to hydrogenate $\alpha$-linolenic acid to predominantly trans-octadec-11-enoic acid which is then used as substrate by a second bacterium. Cultures grown from small mixed inocula failed, with the exception of one pair of bacteria, to hydrogenate $\alpha$-linolenic acid to stearic acid. The products from these cultures showed that one of the pair of bacteria had outgrown the other. For stearate production it was necessary to use inocula with a minimum number of cells rather than cells in a particular phase of growth. Two of the bacteria used, P2/2 and T344, after several years in pure culture show an increased isomerization of the octadecenoic acid products.

\section{INTRODUCTION}

The major esterified fatty acid in the diet of a ruminant on pasture in temperate regions is $\alpha$ linolenic acid, which is rapidly liberated as the free acid by the phospholipases and glycolipases present in the rumen microorganisms (Dawson \& Kemp, 1970). The free acid is conjugated to cis,trans,cis-octadec-9,11,15-enoic acid and then hydrogenated via trans,cis-octadec-11,15-enoic acid and trans-octadec-11-enoic acid to stearic acid by the bacteria, though a small amount of the penultimate reduction product, trans-octadec-11-enoic acid, escapes reduction (Dawson \& Kemp, 1970). Intermediates, in vivo and in vitro, of this sequential reduction have been isolated and characterized (Kemp \& Dawson, 1968; Dawson \& Kemp, 1970) and several bacteria isolated from the rumen shown to hydrogenate $\alpha$-linolenic acid in vitro by the same pathway as mixed rumen bacteria (Kepler et al., 1966; Kemp et al., 1975; Hazlewood et al., 1976; Hazlewood \& Dawson, 1979) but only to an octadecenoic acid; either predominantly transoctadec-11-enoic acid or cis- and trans-octadec-15-enoic acid. Rumen bacteria which hydrogenate unsaturated fatty acids may be conveniently and unambiguously placed in one of two groups depending on the substrates hydrogenated and the products (Table 1). Most bacteria isolated are in the first group (A). They cannot hydrogenate octadecenoic acids, but they hydrogenate linoleic acid and $\alpha$-linolenic acid to trans-octadec-11-enoic acid and related isomers (though some bacteria yield predominantly trans,cis-octadec-11,15-enoic acid from $\alpha$-linolenic) (Hazlewood et al., 1979). Only three bacteria are known in the second group (B); they are characterized by their ability to hydrogenate many octadecenoic acids, including oleic acid, trans-octadec-11-enoic acid and linoleic acid, to stearic acid. The products from $\alpha$-linolenic acid are predominantly cis- and trans-octadec-15-enoic acids which are not further hydrogenated even by mixed rumen micro-organisms (Kemp et al., 1975).

A mechanism involving two bacteria to hydrogenate $\alpha$-linolenic acid to stearic acid has been considered likely for many years (Dawson \& Kemp, 1970), but it was important to demonstrate this, unambiguously, using a simple in vitro system. 
Table 1. Tentative grouping of rumen bacterial isolates used in this investigation based on the unsaturated fatty acid substrates hydrogenated and the products

Group and organism

A F2/6 (Ruminococcus albus) S2 (Butyrivibrio sp.)

B P2:2 (Fusocillus babrahamensis)
T344 (Fusocillus sp.)
R8:5 (Gram-negative rod) $\left\{\begin{array}{l}18: 1 ; \text { cis } 9 \text {, cis } 11 \text {, trans } 9 \\ \text { trans } 11 \\ 18: 2 ; \text { cis } 9 \text {, cis } 12 \\ 18: 3 ; \text { cis } 9, \text { cis } 12 \text {, cis } 15\end{array}\right.$
Substrate

Major products

\author{
(18:1; cis 9, cis 11, trans 9, Not hydrogenated \\ $\left\{\begin{array}{l}\text { trans } 11 \\ 18: 2 ; \text { cis } 9 \text {, cis } 12\end{array}\right.$ \\ $18: 3$; cis 9 , cis 12 , cis 15
18:1; trans 11 (+trans 10 with F2/6)
$18: 1 ;$ trans 11 (trans 10 and $18: 2$; \\ trans 11 , cis 15 with F2/6)
}

Stearic acid $(30 \%$ hydroxystearic acid with cis 9 and $\mathrm{P} 2 / 2$ )

Stearic acid

$18: 1$; cis 15 , trans $15(+$ cis/trans 13,14 and 16 with $P 2 / 2$ and T344)

\title{
METHODS
}

Culture of bacteria. The medium, low in fatty acids, used for both maintenance and experimental cultures contained ( $\left(\mathrm{I}^{-1}\right)$ : Bactocasitone (Difco), 10 ; yeast extract (Difco), $2.5 ; \mathrm{KH}_{2} \mathrm{PO}_{4}, 0.45 ; \mathrm{K}_{2} \mathrm{HPO}_{4}, 0.45 ; \mathrm{NaCl}, 0.9$; $\left(\mathrm{NH}_{4}\right)_{2} \mathrm{SO}_{4}, 0.9 ; \mathrm{MgSO}_{4} .7 \mathrm{H}_{2} \mathrm{O}, 0 \cdot 09 ; \mathrm{CaCl}_{2} .2 \mathrm{H}_{2} \mathrm{O}, 0.12 ;$ resazurin, 0.01 and soluble starch, $1 \cdot 0$. Decanoic acid and palmitic acid, dissolved in a small volume of methanol, were added prior to autoclaving $\left(115^{\circ} \mathrm{C}\right.$ for $20 \mathrm{~min}$ ) to concentrations of $0.01 \mathrm{~g} \mathrm{I}^{-1}$ each. The filter-sterilized reducing medium contained $\left(\mathrm{g}^{-1}\right):$ glucose, 0.5 ; galactose, 0.5 ; cellobiose, 0.5 ; cysteine. $\mathrm{HCl}, 1.0$ and $\mathrm{NaHCO}_{3}, 8.0$. Some experimental media had increased concentrations of galactose, $1.5 \mathrm{~g} \mathrm{I}^{-1}$, or palmitic acid, $0.03 \mathrm{~g} \mathrm{l}^{-1}$, or both. All concentrations given are those in the complete medium, which had a pH of 6.8 when equilibrated with a $100 \% \mathrm{CO}_{2}$ gas phase. All media were prepared and inoculated by the open-tube method under an atmosphere of sterile $\mathrm{O}_{2}$-free $\mathrm{CO}_{2}$ (Hungate, 1969; Latham \& Sharpe, 1971). Cultures were incubated at $39^{\circ} \mathrm{C}$. Two group A bacteria, F2/6 (Ruminococcus albus NCIB 10837) (Kemp et al., 1975) and Butyrixibrio S2 (Hazlewood \& Dawson, 1979), and three group B bacteria, P2/2 (Fusocillus babrahamensis NCIB 10838), T344 (Fusocillus sp. NCIB 11026) (Kemp et al., 1975; White et al., 1974) and R8/5 (unidentified Gram-negative rod; Hazlewood et al., 1976) were stored at $3^{\circ} \mathrm{C}$ on agar $\left(20 \mathrm{~g} \mathrm{l}^{-1}\right)$ slopes, in liquid medium at $3^{\circ} \mathrm{C}$ for up to a month or deep frozen at $-70^{\circ} \mathrm{C}$ for up to 6 months. Subculturing was done monthly. Growth was assessed by measuring the optical density of cultures using an EEL colorimeter (Evans Electroselenium, Halstead, Essex, UK) and relating these values to the dry weights of washed cells.

Preparation of substrate. $\alpha$-Linolenic acid (Sigma $99 \%$ ) (20 mg per 1 of medium) and $\alpha-\left[1-{ }^{14} \mathrm{C}\right]$ linolenic acid [ $54 \mathrm{mCi} \mathrm{mmol}^{-1}\left(20 \mathrm{GBq} \mathrm{mmol}{ }^{-1}\right)$, Amersham] $\left(50 \mu \mathrm{Ci}^{-1}\right)$ dissolved in methanol $(20 \mu \mathrm{l})$ were distributed into cultures tubes containing $0.5 \mathrm{ml}$ unreduced medium and the tubes closed with cotton-wool plugs and sterilized. Whilst still hot the tubes were either filled with hot sterile reduced medium or gassed with sterile $\mathrm{O}_{2}$-free $\mathrm{CO}_{2}$ and closed with butyl-rubber stoppers for the later addition of growing culture.

Analysis of products. The extraction of lipids from the experimental cultures, the subsequent hydrolysis and methylation of free fatty acids and analysis of their methyl esters by TLC and GLC were essentially as described by Kemp et al. (1975). Peak areas from GLC mass traces of methyl ester analyses were obtained using a Hewlett Packard 3380A integrator or by the method of Carroll (1961). Peak areas from radio-gas chromatographic traces were obtained either by triangulation or using a scaler which, because of the background signal, gave better reproducibility between duplicates than using the integrator.

\section{RESULTS AND DISCUSSION}

Recovery of ${ }^{14} \mathrm{C}$-labelled fatty acids from cultures after incubation with $\alpha-\left[1-{ }^{14} \mathrm{C}\right]$ linolenic acid was the same as from controls and was in the range 95-105\%. Specific activities were not determined; ${ }^{14} \mathrm{C}$ was used primarily to aid the recovery and to simplify the structural analyses of products.

Fatty acids, as methyl esters, accounted for $85 \%$ (range $\pm 5 \%$ ) of the recovered radioactivity. Some activity $\left(6 \cdot 1 \pm 2 \%\right.$ ) was lost in the aqueous washings of the $\mathrm{CHCl}_{3} /$ methanol extract, from which only fatty acids were identified after refluxing the dried extract with $6 \% \mathrm{KOH}$ in $95 \%$ aq. methanol $(\mathbf{w} / \mathrm{v} / \mathrm{v})$.

In the basal medium with cultures of strains P2/2, T344, R8/5 and F2/6 loss of activity into the non-saponifiable fraction was 4-5\%, but with strain S2 and mixed cultures of strain S2 with group B strains losses were in the range 6-17\%. The higher values were recorded when the high 
Table 2. Position and geometry of the double bonds of the octadecenoic acids resulting from the hydrogenation of $\alpha$-linolenic acid by bacteria P2/2, T344, R8/5, S2 or F2/6

\begin{abstract}
Media containing $\alpha$-linolenic acid $\left(20 \mathrm{mg} \mathrm{1}^{-1}\right)$ were inoculated and incubated for $16 \mathrm{~h}$. Lipids were extracted and hydrolysed and the fatty acids were methylated and analysed by GLC and TLC. Values are shown as percentages $(w / w)$; for $18: 1$ as a percentage of the total $C_{18}$ fatty acids, and for positional isomers as the percentage of dicarboxylic acid dimethyl esters obtained by oxidation of the cis- and trans-octadecenoic acids. Figures for the total $\mathrm{C}_{18}$ acids recovered as a percentage of the substrate used are given in the text.
\end{abstract}

\begin{tabular}{|c|c|c|c|c|}
\hline Bacterium & $18: 1(\%)$ & $\Delta^{*}$ & $18: 1$ cis $(\%)$ & $18: 1$ trans $(\%)$ \\
\hline $\mathrm{P} 2 / 2$ & 95 & $\begin{array}{l}11 \\
12 \\
13 \\
14 \\
15 \\
16\end{array}$ & $\begin{array}{c}\text { tr } \\
\text { tr } \\
0.2 \\
1.0 \\
15.2 \\
3.6\end{array}$ & $\begin{array}{r}0.8 \\
1.6 \\
5.2 \\
18.9 \\
42.1 \\
11.4\end{array}$ \\
\hline T344 & 85 & $\begin{array}{l}12 \\
13 \\
14 \\
15 \\
16\end{array}$ & $\begin{array}{r}0.2 \\
1.8 \\
2.1 \\
17 \cdot 1 \\
3.8\end{array}$ & $\begin{array}{c}\text { tr } \\
8 \cdot 1 \\
18 \cdot 2 \\
39 \cdot 1 \\
9 \cdot 6\end{array}$ \\
\hline $\mathrm{R} 8 / 5$ & 60 & 15 & 65 & 35 \\
\hline $\mathbf{S} 2$ & $>95$ & 11 & - & 100 \\
\hline $\mathrm{F} 2 / 6 \dagger$ & 20 & $\begin{array}{l}10 \\
11\end{array}$ & $\begin{array}{l}10 \\
10\end{array}$ & $\begin{array}{l}40 \\
40\end{array}$ \\
\hline
\end{tabular}

galactose medium was used, presumably because there was insufficient palmitate to meet the needs of strain S2 for fatty acids (Hazlewood \& Dawson, 1979). In the two media containing a high palmitate concentration, losses were no more than 6-7\%, even though there was increased growth. The non-saponifiable fractions from incubations of strain S2 contained trans-octadec11-enoic acid and aldehyde derived from this acid. Only traces of the characteristic dicarboxylic acids derived from trans-octadec-11-enoic acid were detected in the products (Hazlewood \& Dawson, 1979; Klein et al., 1979).

Examination of the growth of strains P2/2, T344, R8/5 and S2 in the basal medium using an automatic colorimeter (Hazlewood et al., 1979) showed maximum optical density readings of $0.95,1 \cdot 3,1.8$ and $1 \cdot 1$ for the four strains at $16,18,12$ and $16 \mathrm{~h}$ respectively. Half-maximal growth was found at $9,11,7$ and $9 \mathrm{~h}$ respectively. Strain F2/6 grew very poorly and cultures rarely had an optical density exceeding 0.3 at $22 \mathrm{~h}$. In the basal medium, dry weights of washed cells recovered from a culture with an optical density of 1.0 were $\left(\mathrm{mg} \mathrm{ml}^{-1}\right): \mathrm{P} 2 / 2,0.33 ; \mathrm{T} 344,0.34 ; \mathrm{R} 8 / 5,0.42$; and $S 2,0 \cdot 32$.

The growth of strain S2 was stimulated $50 \%$ by increased galactose or palmitic acid concentration $(3 \times$ basal $)$ and $100 \%$ by increasing both. There was a $20 \%$ stimulation of the growth of strain $\mathrm{S} 2$ by $\alpha$-linolenic acid in the basal medium and in the high galactose medium. The growth of strain P2/2 was stimulated by $50 \%$ by increased galactose concentration, but not by increased palmitic acid concentration; the effect of $\alpha$-linolenic acid was variable.

\title{
Hydrogenation by pure cultures
}

The values for the overall hydrogenation of $\alpha$-linolenic acid (Table 2) by $16 \mathrm{~h}$ cultures of the five bacteria agreed with those reported previously (Kemp et al., 1975; Hazlewood et al., 1976; Hazlewood \& Dawson, 1979), except for strain F2/6, which showed only $20 \%$ conversion to octadecenoic acids, as compared with a previous $50 \%$, the major product being trans, cisoctadec-11,15-enoic acid. The products from strains P2/2 and T344 showed a wider range of cis 
and trans octadecenoic acids than the original data (Kemp et al., 1975). In case these results might have been due to contamination, P2/2 and T344 were repurified and compared with cultures held at the National Collection of Industrial Bacteria (Torry Research Institute, Aberdeen, UK) since 1973 (White et al., 1974). No contamination was found and only minor differences were found in the hydrogenation of oleic acid and $\alpha$-linolenic acid. Cultures of strains P2/2 and T344 were also incubated either with cis-octadec-15-enoic acid, prepared from R8/5 cultures grown with $\alpha$-linolenic acid, or with trans,cis-octadec-11,15-enoic acid from F2/6 cultures grown with $\alpha$-linolenic acid. The products were very similar to those obtained with $\alpha$ linolenic acid as substrate and it is certain that strains P2/2 and T344 have an isomerase, more active than in earlier experiments, which converts cis-octadec-15-enoic acid to related cis and trans isomers (Table 2).

\section{Hydrogenation by mixed cultures}

Cultures grown from a small mixed inoculum, containing approximately equal numbers of a group $A$ bacterium and a group $B$ bacterium, showed little more growth than the stronger grower of the two grown in pure culture. Strain S2 (A) outgrew strains P2/2, T344 and R8/5 (B) and these three outgrew strain F2/6 (A) in mixed cultures. The products of $\alpha$-linolenic acid hydrogenation were typical of the dominant organism (Table 2 ) and only the mixture $S 2+$ P2/2 produced any stearic acid $(5 \%)$. Similar results were obtained with mixed cultures grown for $16 \mathrm{~h}$ before mixing with $\alpha$-linolenic acid, but no stearic acid was detected.

\section{Conditions for stearate production}

Mixing cultures of strain S2 and one of the group B bacteria, both grown for $16 \mathrm{~h}$ (late exponential phase), and incubating with $\alpha$-linolenic acid for $5 \mathrm{~h}$ gave excellent yields of stearic acid (Table 3). The yield of stearic acid together with the residual octadecenoic acids $\left(\Delta^{9}, \Delta^{10}\right.$, $\Delta^{\prime \prime}$ and possibly $\left.\Delta^{12}\right)$, which arise primarily because of the hydrogenation of $\alpha$-linolenic acid by strain S2, gives an indication of the ability of strain $\mathbf{2} 2$ to compete for $\alpha$-linolenic acid and trans, cis-octadec-11,15-enoic acid. The proportions of these products arising from the activity of strain S2 in mixed cultures were: with P2/2, 70.1\%; with T344, 72.9\%; and with R8/5, 99.1\% (Table 3). The $\Delta^{9}, \Delta^{10}$ and $\Delta^{12}$ octadecenoic acids may be due to the isomerase associated with strains P2/2 and T344 since these isomers were absent from the products of incubations of strains S2 + R8/5. Preincubation of strain S2 with substrate for 30 min before adding strains $\mathrm{P} 2 / 2$ or T344 slightly increased the products attributable to $S 2$ activity. With strain F2/6, even after preincubation, only $1 \cdot 2 \%$ (i.e. the trans 11 isomer) of the products could be due to activity of strain F2/6 in mixed cultures with strain P2/2.

Since very little stearic acid was produced from $\alpha$-linolenic acid by cultures grown from mixed inocula, yet cultures mixed after $16 \mathrm{~h}$ growth gave high yields of stearic acid, $5 \mathrm{ml}$ broths were inoculated with either strain S2 or strain T344 and grown for periods up to $18 \mathrm{~h}$ before mixing and adding to a suspension of $\alpha$-linolenic acid. Mixing immediately after inoculation followed by incubation for $24 \mathrm{~h}$ gave almost $100 \%$ trans-octadec-11-enoic acid (Table 4). A $3 \mathrm{~h}$ preincubation before mixing yielded several components, among which trans-octadec-11-enoic acid was predominant ( $>90 \%$ ); there was only a trace of stearic acid. A $6 \mathrm{~h}$ preincubation showed $25 \%$ conversion to stearic acid. Preincubation for $9 \mathrm{~h}$, and longer times, prior to mixing yielded conversions that were similar to one another. Up to $6 \mathrm{~h}$ preincubation yielded products in which the major octadecenoic acid was trans-octadec-11-enoic acid but at later times there was a marked contribution from octadecenoic acid isomers typical of hydrogenation by strain T344. cis-Octadecenoic acids were detected in insufficient amounts $(<5 \%)$ to allow determination of their double bond positions. Mixtures of strains S2 and P2/2 gave comparable results to mixtures of S2 and T344, except that stearic acid was detected earlier, after $0 \mathrm{~h}$ or $3 \mathrm{~h}$ preincubation ( $2 \%$ and $5 \%$ of the products, respectively), and octadecenoic acids with double bonds in positions 12-16, typical of hydrogenation by strain P2/2, were obvious after a $6 \mathrm{~h}$ preincubation. These data suggested that the age of the culture or the number of cells used in the inoculum might be important. 

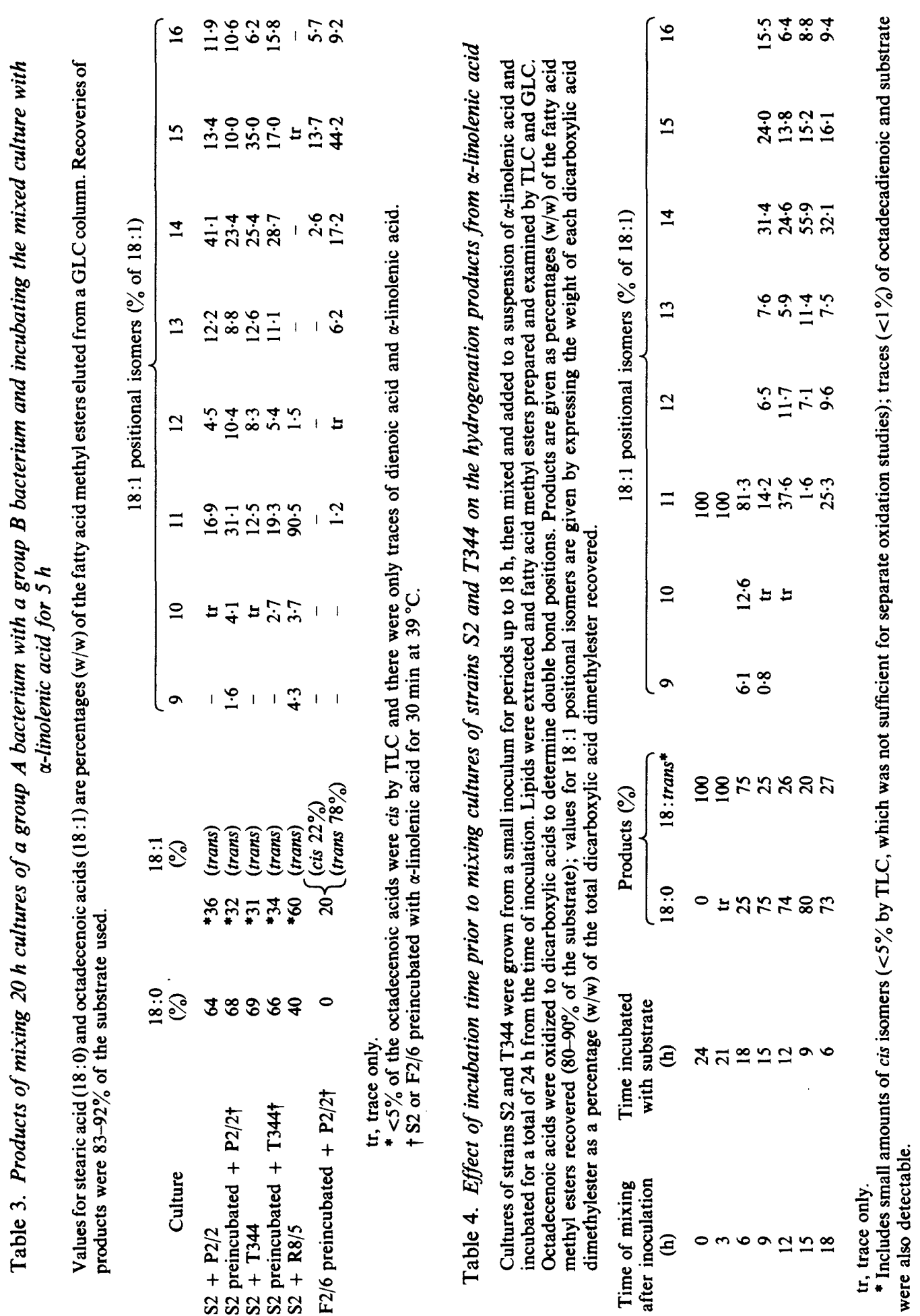
To clarify this the hydrogenation of $\alpha$-linolenic acid was examined by mixing similar inocula of either $5.0,1.5,0.5$ or $0.1 \mathrm{ml}$ from $16 \mathrm{~h}$ cultures of strains S2 and P2/2 of similar cell density. Four media were used: the basal medium, and the basal medium with three times the normal concentration of galactose $\left(1.5 \mathrm{~g} \mathrm{l}^{-1}\right)$, of palmitic acid $\left(30 \mathrm{mg} \mathrm{l}^{-1}\right)$, or of both. The last three media were expected to stimulate the growth of strain $\mathrm{S} 2$ relative to that of strain $\mathrm{P} 2 / 2$. The mixtures of $\mathrm{S} 2+\mathrm{P} 2 / 2$ were added to $\alpha$-linolenic acid $(200 \mu \mathrm{g})$, suspended in $0.5 \mathrm{ml}$, together with sufficient medium to give a final culture of $10.5 \mathrm{ml}$. Incubations were for $20 \mathrm{~h}$ which, being longer than necessary to reach stationary phase $(16 \mathrm{~h})$, would reduce differences between treatments. In this experiment, using inocula of $0.1,0.5,1.5$ and $5 \mathrm{ml}$ from $16 \mathrm{~h}$ cultures gave nearly the same cell numbers prior to incubation as mixing cultures that had been growing for $1 \cdot 5,4,7$ and $16 \mathrm{~h}$ (maximum cell density), respectively. A rough comparision may therefore be made between the results from the cultures preincubated for similar times $(0,3,6$ and $15 \mathrm{~h})$ in the previous experiment (Table 4), and those from the $16 \mathrm{~h}$ cultures with different volumes of inocula. After incubation for $20 \mathrm{~h}$ there was $1-2 \%$ of residual substrate and $4-6 \%$ of trans, cisoctadec-11,15-enoic acid. The rest of the $\mathrm{C}_{18}$ acids recovered were stearic acid and octadecenoic acid isomers. The latter were predominantly trans $-\Delta^{11}$ isomers with the exception of the $5 \mathrm{ml}$ inocula, which showed a large contribution from $\Delta^{13}-\Delta^{16}$ isomers indicating a contribution by strain P2/2 to the hydrogenation. In all four media the production of stearic acid was highest with the $5 \mathrm{ml}$ inocula. The figures for stearic acid were (in the order basal medium, high palmitate, high galactose, high palmitate + high galactose): $5 \mathrm{ml}$ inocula, 68, 63, 47 and $38 \%$; $1.5 \mathrm{ml}$ inocula, $27,21,9$ and $8 \% ; 0.5 \mathrm{ml}$ inocula, $12,7,7$ and $5 \%$; and $0.1 \mathrm{ml}$ inocula, $2.5 \%$ in the basal medium and less than $1 \%$ in the other three. A comparison of the times and values in Table 4 with the data above for the basal medium shows them to be close enough to indicate that the numbers of cells in the inocula are probably more important than the phase of growth of the cells. Stimulating growth of strain $\mathrm{S} 2$ in the mixed culture appears to be at the expense of the growth of strain P2/2, and stearate production is depressed. Inocula from cultures stored for $1.3 \mathrm{~d}$ at $4{ }^{\circ} \mathrm{C}$ or $-70^{\circ} \mathrm{C}$ gave variable and poorer conversions than fresh cultures.

The failure to produce stearic acid in cultures grown from small inocula is probably because one organism outgrows the other. For high yields of stearic acid it must be necessary to strike a balance between the number of each bacterium in the culture and the affinity of each for $\alpha$ linolenic acid such that the substrate is hydrogenated by the group $A$ bacterium to trans-octadec11-enoic acid which can be hydrogenated to stearic acid by group B bacteria. This balance is almost right with strains S2 + R8/5 (see Table 3) and for strains S2 + T344 at 6 h (Table 4), but has proved elusive when deliberate steps have been taken to achieve this end. In the rumen group B organisms octadecenoic acid production rarely exceeds $1-2 \%$ of the total octadecenoic acids and is frequently undetectable (Dawson \& Kemp, 1970); but see Body (1976).

The hydrogenation of $\alpha$-linolenic acid to stearic acid by mixed cultures was not unexpected since it is well known that trans-octadec-11-enoic acid is readily hydrogenated to stearic acid by mixed rumen bacteria and by three bacteria isolated from the rumen (Dawson \& Kemp, 1970; Kemp et al., 1975). It would appear simpler for one organism to contain the whole complement of enzymes rather than for two to do so and thus duplicate most of the system; both groups $A$ and $B$ can produce and hydrogenate trans,cis-octadec-11,15-enoic acid. However, the two-organism system may allow more versatility to deal with a wider range of substrates. The $\Delta^{12}$-cis- $\Delta^{11}$-trans isomerase isolated by Kepler \& Tove (1967) is located in the cell envelope so one might reasonably expect the hydrogenation enzymes to be similarly placed to facilitate transfer of the free fatty acid substrates. The most intriguing problem is how trans-octadec-11-enoic acid is transferred from a group A bacterium to a group B, there being no obvious reasons why these two bacteria should be found in close association in the rumen. Neither needs to hydrogenate to survive in vitro, but in the rumen where unsaturated fatty acid concentrations are higher their toxicity could be a problem (Nieman, 1954), and without ruminal hydrogenation the ingestion of large amounts of unsaturated acids leads to myopathic lesions unless an adequate intake of vitamin $\mathrm{E}$ is maintained (Blaxter, 1957).

Relative numbers of the five bacteria used in our experiments are difficult to assess in the rumen; in pure culture individual group A and B bacteria can be distinguished morphologically 
but this is difficult in mixed cultures and impossible in rumen contents. Insufficient work has been done to allow us to use selective media. Knowing the dilutions of rumen fluid used in the original isolations is of doubtful value for comparative work: strains P2/2, T344 and F2/6 were isolated at $10^{7}-10^{8}$ dilutions and strain $\mathrm{S} 2$ at $10^{9}$; the dilution for strain R8/5 was not closely specified but in the range $10^{8}-10^{10}$. Five different sheep were used and the isolation procedure for strains $\mathrm{S} 2$ and R8/5 used different media and more carefully maintained anaerobic conditions.

\section{REFERENCES}

BLAXTER, K. L. (1957). Myopathic conditions in animals. Veterinary Record 69, 1150-1155.

BODY, D. R. (1976). The occurrence of cis-octadec-15enoic acid as a major hydrogenation product of methyl linolenate in bovine rumen liquor. Biochemical Journal 157, 741-744.

Carroll, K. K. (1961). Quantitative estimation of peak areas in gas-liquid chromatography. Nature, London 191, 377-378.

Dawson, R. M. C. \& KemP, P. (1970). Biohydrogenation of dietary fats in ruminants. In Physiology of Digestion and Metabolism in the Ruminant, pp. 504 518. Edited by A. T. Phillipson. Newcastle upon Tyne, Oriel Press.

Hazlewood, G. P. \& Dawson, R. M. C. (1979). Characteristics of a lipolytic and fatty acid-requiring Butyrivibrio sp. isolated from the ovine rumen. Journal of General Microbiology 112, 15-27.

Hazlewood, G. P., KeMP, P., LANDER, D. \& Dawson, R. M. C. (1976). $C_{18}$ unsaturated fatty acid hydrogenation patterns of some rumen bacteria and their ability to hydrolyse exogenous phospholipid. British Journal of Nutrition 35, 293-297.

Hazlewood, G. P., Reynolds, M. J., Dawson, R. M. C. \& Gunstone, F. D. (1979). An automatic colorimeter and its use in evaluating the growth response of an anaerobic general fatty acid auxotroph to cis- and trans-octadecenoic acids. Journal of Applied Bacteriology 47, 321-325.

Hungate, R. E. (1969). A role tube method for the cultivation of strict anaerobes. Methods of Microbiology 3B, 117-132.

KEMP, P. \& DAwsON, R. M. C. (1968). Isomerisation of linolenic acid by rumen micro-organisms. Biochemical Journal 109, 477-478.
Kemp, P., White, R. W. \& LANDER, D. J. (1975). The hydrogenation of unsaturated fatty acids by five bacterial isolates from the sheep rumen, including a new species. Journal of General Microbiology 90, 100114.

KEPLER, C. R. \& Tove, S. B. (1967). Biohydrogenation of fatty acids. III. Purification and properties of linoleate $\Delta^{12}$-cis- $\Delta^{11}$-trans-isomerase from Butyrivibrio fibrisolvens. Journal of Biological Chemistry 242, 5686-5692.

KePler, C. R., Hirons, K. P., MCNeill, J. J. \& Tove, S. B. (1966). Intermediates and products of the biohydrogenation of linoleic acid by Butyrivibrio fibrisolvens. Journal of Biological Chemistry 241, 1350-1354.

Klein, R. A., Hazlewood, G. P., Kemp, P. \& DAwson, R. M. C. (1979). A new series of long-chain dicarboxylic acids with vicinal dimethyl branching found as major components of the lipids of Butyrivibrio spp. Biochemical Journal 183, 691-700.

Latham, M. J. \& Sharpe, E. M. (1971). The isolation of anaerobic organisms from the bovine rumen. In Isolation of Anaerobes, pp. 133-147. Edited by D. A. Shapton \& R. G. Board. London: Academic Press.

NiEMAN, C. (1954). Influence of trace amounts of fatty acids on the growth of microorganisms. Bacteriological Reviews 18, 147-167.

White, R. W., MacKenzie, H. R. \& Bousfield, I. J. (1974). Successful freeze-drying and retention of biohydrogenation activity of bacteria isolated from the bovine rumen. Journal of Applied Bacteriology 37, vi. 